\title{
Cell Migrations to the Isocortex in the Rat '
}

\author{
SAMUEL P. HICKS AND CONSTANCE J. D'AMATO \\ Department of Pathology, University of Michigan Medical Center, \\ Ann Arbor, Michigan
}

\begin{abstract}
Cells that took up tritiated thymidine ( $\mathrm{H}-3 \mathrm{~T}$ ) at various periods of intrauterine and early infant life in the periventricular proliferative zone and migrated to form the isocortex in the rat were tracked autoradiographically in series of stages to characterize their movements. Cells labeled at any stage soon separated themselves into cohorts, some continuing to proliferate, others migrating at once, and still others delaying before migrating. Migratory cells moved to the developing cortex along the curved and oblique paths of the pallial fibers, whose basic plan was established by the early thalamocortical fibers. Magnitude of speed was 15 to $30 \mu$ per hour. The primitive neural cells that originated on each of the fourteenth to eighteenth in. trauterine days first reached the cortex in about 48 hours, others took two or three days longer. Migrations originating on the nineteenth to twenty-first days continued into the week after birth; as the primitive cells approached the cortex, however, they differentiated into young neurons, and traveled perpendicularly to its outer part. The first cohort of twentieth day labeled cells reached their intracortical destinations in about three days, the last in about ten days. The isocortex was formed essentially from within outward. The first neuroglia destined for the isocortex arose on the twenty-first intrauterine day.
\end{abstract}

Radiation and tritiated thymidine (H-3T) have been used to map the positions of migrating neural cells in the brain in succeeding stages of embryos and postnatal animals, to trace out parts of the migrations. Both methods have shown that the isocortex of rats and mice is laid down largely from the deepest layers outward (Angevine and Sidman, '61, '62; Sidman and Angevine, '62; Hicks, D'Amato and Lowe, '59; Berry and Rogers, '65; D'Amato and Hicks, '65). Neither has revealed the paths followed by the moving cells, their transit times to their destinations, or the order and manner in which they arrive in the cortex (Hicks, '58; Hicks, D'Amato, Coy, O'Brien, Thurston and Joftes, '61; Hicks and D'Amato, '61). To begin to find answers to these problems of migration and developing cell relationships, H-3T was given to pregnant rats carrying litters at a number of intrauterine stages or to infant rats. The successive positions of the cells labeled with H-3T were followed autoradiographically, step by step, as they moved from their origins in the proliferative zones to their destinations in the brains of a succession of members of each litter. This paper describes some of the movements that these cells made to the isocortex, inferred from these successive positions.

\section{MATERIALS AND METHODS}

Pregnant rats were given $\mathrm{H}-3 \mathrm{~T}$ on the fourteenth, or on one of the sixteenth to twenty-second days of gestation, and infant rats from newborn to six days old. Fetuses, infants and older animals were killed at intervals and autoradiographs of microscopic sections of their brains were made. Two to five litters were used for each day, each sampled at several stages, usually two animals at each stage. Methods of timing pregnancies, surgically removing fetuses from one litter at intervals of hours or days and leaving some to be born for study at later stages has been described (Hicks, '54; Hicks and D'Amato, '66). Birth usually occurred between the twentysecond and twenty-third day. The intervals sampled after $\mathrm{H}$-3T were such that one, five, 24, 48, 72 and 96 hours, newborn or one day, five, seven and 25 days, and six weeks old were represented, often more than once, in prenatal series, and nearly comparable ones after birth. Two, three, four, eight, nine and 11 hours, ten days and nine weeks samples were sometimes made.

Most rats were the Fl cross (Irish) between an albino and a black-selfed non-

1 This work was supported by USPHS grant NB03861 and AEC Contract AT (11-1)1201. 
agouti line, brother-sister mated more than 40 generations. A few experiments were with the albino line, originally begun to study mitotic cycles and initial migratory movements (Hicks et al., '61).

Fixation was in Bouin's fluid with $10 \%$ formalin. Paraffin sections were cut $5 \mu$ thick, except $8 \mu$ in animals three and onehalf weeks or older. Serial sections were made of younger fetuses, of the heads or brains of older ones; brains of postnatal animals were serially sectioned, or divided into blocks and partly sectioned. For most stages both frontal and sagittal sections were made. Sections were dipped in Kodak NTB-2 Nuclear Track Emulsion, and held in cold, dry $\mathrm{CO}_{2}$ atmosphere usually three or six weeks. Cresyl violet usually, Cason's and Cajal's pyridine silver nitrate sometimes, were used.

Methods of study included mapping positions of labeled cells on outline drawings of projected autoradiographed sections, and making composite models using colored map pins to represent successive positions of migrating cells that originated each day. Autoradiographed sections were compared with corresponding sections, variously dyeor silver-stained, of an extensive series of rat brains in pre- and postnatal stages.

Cells taking up H-3T were assumed to pass, on average, half the label to each daughter cell, these halved it again to granddaughters, and so on. In any autoradiograph, cells were relatively classed as labeled, lightly labeled, or not labeled. The labeled cells ("moderately to heavily," or "substantially" labeled in comparison to lightly labeled) were considered to have originated at the time $\mathrm{H}-3 \mathrm{~T}$ was given, and to have begun their migrations usually after none or one division; they are the "labeled cells" being tracked in the descriptions that follow. Lightly labeled cells were disregarded, in this context, as members of later generations, the result of several divisions, but they are specifically mentioned where keeping track of later generations is important. Factors were considered that could cause deviations from ideal intensity of labeling: whether a cell entered DNA synthesis phase (s-phase) too late to capture a full H-3T label, variation in length of s-phase (Hicks et al., '61), and changes in nuclear size and shape during differentiation. Errors from these sources were considerably avoided by following the progress of populations of labeled cells at the frequent intervals provided by the experiments.

Usually $4 \mu \mathrm{c}$ H-3T solution were given intraperitoneally per gm body weight (Schwartz BioResearch, Sp Act $3 \mathrm{c} / \mathrm{mmole}$, $1000 \mu \mathrm{c}$ per $\mathrm{ml}$ ); except: intracardiac in the albino series to assure brief exposure for hourly studies of mitotic cycles; and in divided doses, three injections in two hours, in two crossbred pregnant animals (17 and 20 days).

$\mathrm{H}-3 \mathrm{~T}$ irradiates the structures into which it is incorporated (Bond and Feinendegen, '66), but we recognized no pathologic effects of the $4 \mu \mathrm{c}$ doses. An additional experiment with $16.4 \mu \mathrm{c}$, like the other single dose seventeenth day experiments, was done in search of pathologic effects.

\section{RESULTS}

These may be presented mainly as (1) a summary of destinations in the isocortex of labeled cells that originated on various days of fetal and infant life, and (2) a description of certain migrations to these destinations based on plotting the successive positions of the labeled cells in autoradiographed material, and on observations of conventional histologic material. A brief note, (3), on the $16.4 \mu \mathrm{c}$ experiment concludes the RESUcts. Representative migrations and destinations are diagrammed in figure 1; photomicrographs form plate figures $2-5$.

Isocortex indicates "six-layered cortex" from the border of the cingular cortex dorsomedially over the vertex laterally to the rhinal fissure, including areas $18 \mathrm{a}$ of the occipital pole and 10 and 8 of the frontal pole as diagrammed for rats by Krieg

Abbreviations

C, cortex, cortical plate

M, MIG, migratory zone

MI, mitotic zone of the periventricular proliferative zone

OU, outer cortex, presumptive layers II, III, IV

$P$, periventricular proliferative zone

pVI, deepest, or polymorphous cell part of layer VI

S, synthesis-phase zone of the periventricular proliferative cell zone

I. II, III, etc., layers of the isocortex 


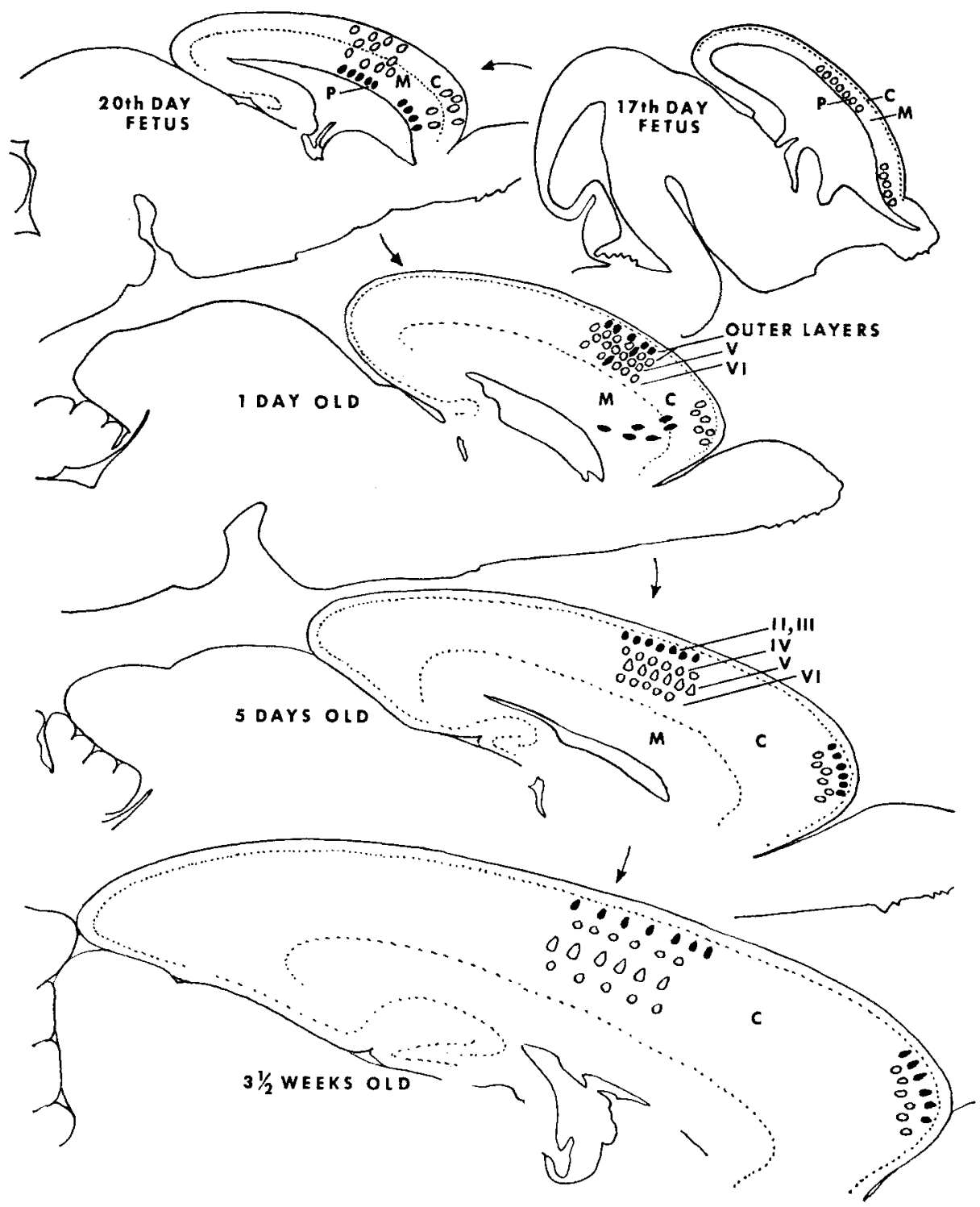

Fig. 1 Diagram of migrations of H-3T labeled cells in the rat brain, that originated on the seventeenth (ovals) or twentieth intrauterine day (black). The movements of small samples of cells are represented by their successive positions in outline tracings of sagittal sections of the brains at the stages shown, drawn to the same scale. $\times 20$. P, periventricular proliferative cell zone; $\mathrm{C}$, developing cortex; $\mathrm{M}$, migratory zone or album cerebri. The cells originating in the proliferative zones are represented in single rows, and some are assumed to have divided. The seventeenth day labeled cells are migrating toward and arriving in the cortex as the twentieth day cells originate; by the stage of one day old, they have arrived in the layers or presumptive layers they were destined for. Some twentieth day labeled cells have overtaken and passed the seventeenth day cells, at one day, to reach the dorsal outer cortex. Others have delayed, then continued migrating, most of them reaching the frontal cortex by five days after birth. The mature pattern is represented in the three and one-half weeks stage. 
('46). In the mature rat, layer $\mathrm{V}$ with its large neurons usually formed the midzone. Layer VI formed a third to a half the thickness of the cortex; a layer of polymorphous neurons, pVI in illustrations, formed its deepest margin. Layer IV neurons were mostly small; with the larger neurons of layers II and III it formed the "outer cortex."

\section{Destinations of cells migrating to the isocortex}

Cells that originated in the periventricular proliferative zones and began their migrations to the isocortex on the fourteenth intrauterine day became polymorphous neurons of the deepest part of layer VI, more of them in the lateral than the dorsal cortex.

Cells that originated on the sixteenth intrauterine day became neurons in layer VI in the dorsal cortex including some polymorphous cells, but as one moved laterally, labeled cells were distributed more superficially. Dorsolaterally they were concentrated in the outer part of layer VI and in $\mathrm{V}$, and they took more and more superficial positions further laterally, being limited to layers III and II near the rhinal fissure. This shifting distribution, from relatively deeply situated Iabeled neurons dorsally to more superficial ones laterally, was similar throughout the isocortex except that in the frontal and occipital poles, at about the equator, the distribution was deeper like that in the dorsal cortex.

The labeled cells that originated and began migrating on the seventeenth day came to rest in positions more superficial than those of the sixteenth day: dorsally in the outer half of layer VI, and in V and IV; as one moved laterally there were fewer and fewer in VI with a gradual shift in concentration to IV, III, and even II at the rhinal fissure. At the poles, again, the distribution paralleled that in the dorsal, rather than the lateral, cortex.

Cells originating on the twentieth intrauterine day migrated to layers II and III of the dorsal cortex, the concentration falling off laterally toward the rhinal fissure. At the poles they appeared quite superficially in layer II. Cells labeled on the eighteenth and nineteenth days moved to respective positions intermediate between those of the seventeenth and twentieth day, but both contributed substantially to layer IV dorsally, and both had a relatively broad distribution, contributing to layers IV, III, and II dorsally and at the poles. Laterally they were more superficially concentrated with few as deep as IV. Cells originating on the twenty-first day and fated to become neurons went to the outer cortex like those of the twentieth day, but were rare in the frontal pole and scant over the anterior vertex. Only a few cells originating on the twenty-second day became isocortex neurons, coming to rest dorsally in outer layer II.

The first neuroglia destined for the isocortex also originated on the twenty-first day. Virtually all cells originating after the twenty-second day up to several days after birth, and destined for the isocortex, became nueroglia. Because neuroglia destined for different parts of the brain arose at quite different times, divided, changed form (Smart and Leblond, '61) and probably moved about after their initial migration (D'Amato and Hicks, '65), tracking them differed from tracking neurons and only a few aspects of this will be considered.

These final positions of nerve cells indicated that the cortex was largely laid down from the deepest regions outward, but the lateral cortex was more advanced in development at any stage than the dorsal and polar cortices. Traditional cortical layers and cytoarchitectural regions were not laid down in units, and as we will see, the final positions of the labeled cells gave little indication of how and when they got there.

\section{Migrations}

Tracking all of the migratory cells, or even the samples identified by $\mathrm{H}-3 \mathrm{~T}$ labeling, would be impossible, but parts of these populations could be studied. Against a background of certain features of normal pallial development we describe some of the successive positions of the labeled migratory cells to illustrate patterns of their movements.

Normal pallial development. 1. From the twelfth to fourteenth intrauterine days, the early pallia, resembling eccentric hollow spheres, were composed mostly of the 
proliferative cells, but a day later a few cells had moved slightly outward to form a new region that would become the earliest cortex, or cortical plate, with a subjacent migratory zone. Into this region grew the first corticopetal fibers, axones chiefly of neurons in the ventral thalamus, passing first through the rostral bases of the pallia, then fanning out along curved pathways laterally, dorsally and caudally in the pallial walls. This pattern of oblique, indirect, sometimes circuitous paths to the cortex set the basic plan for the later arrangement of fibers to and from the cortex, and recognition of it helps later in understanding why the migratory cells took so relatively long to reach the cortex. The advancing front of the fibers coincided with two progressing morphologic changes: the condensation of a layer of immature neurons, the cortical plate, and the alignment of the migratory cells along the fibers. Cells in the new zone took on the appearance of young neurons just ahead of the invading fibers, becoming radially oriented toward the pallial surface to form a condensed "plate" only after the fibers reached their vicinity or, possibly, contacted them. Concommitantly, the migratory cells arising from the proliferative zone came to lie along the fibers, but just after the advancing fiber front had passed. When the migratory cells arrived at the developing cortical plate, they left the fibers and moved outward through whatever cortex had been formed to thicken it progressively on its outer aspect. About the eighteenth intrauterine day the deep part of layer VI, the polymorphous neurons, began to separate from the rest of the plate laterally, and this was associated with the growth of fibers between them and the outer condensed part of the plate. The fibers penetrated the plate deliberately, not reaching its outer part until nearly a week after birth (Hicks, Cavanaugh and O'Brien, '62).

2. Some dimensions in the developing pallium, though approximate, are significant Iater for estimating speeds and distances traveled by migratory cells. The migratory zone between the sixteenth and seventeenth intrauterine days was about $150 \mu$ wide laterally (fig. 2 ) but just starting to form dorsally. By the twentieth day (fig. 4) it had widened to about $200 \mu$ measured laterally and mid-dorsally, and only a little more by the time of birth. The distance a cell would travel in the deeper part of the migratory zone, if it moved from the lateral periventricular proliferative zone to the dorsal cortical plate, changed remarkably little in this four day period. It was about $1500 \mu$ on the sixteenth to eighteenth days and still only about $1800 \mu$ on the twentieth day. The reason was that the cortex expanded at a much faster rate than the underlying migratory zone, as the more superficial parts of a growing spheroid would expand, compared with deeper parts. In midpallium, dorsolaterally, for example, the cortex grew in thickness nearly linearly from about $100 \mu$ on the eighteenth day to 250 on the twentieth, 600 the day after birth to about $1400 \mu$ at ten days old.

Successive positions of labeled migratory cells. The generations of cells that were tracked showed both common features of migratory behavior and differences. Those originating on the sixteenth to nineteenth intrauterine days showed similar movements during mitotic cycles, the transit times from proliferative zone to cortex were comparable, and they separated themselves into similar kinds of cohorts during the migratory movements. Those of the fourteenth day or twentieth to twenty-second days showed similarities to the sixteenth to nineteenth day group, but there were interesting differences in those that began late in fetal life. A description of some of the steps in the cell movements illustrates where and when many of the cells migrated.

1. Mitotic cycles and early phases of migration. Most of the nuclei of neural cells in the pallium, at any stage, that took up H-3T shortly after it was given were located in the outer part of the periventricular proliferative cell region, the DNA synthesis phase (s-phase) zone. A third to a half of these nuclei moved inward, by contraction of the cell body, to the ependymal surface to divide there within the next few hours, the daughter cell nuclei returning to the s-phase zone by extension of the cells to repeat the process, or begin migrating (Sauer, '35; Sidman, Miale and Feder, '59; Hicks and D'Amato, '66). On 
the seventeenth day, the first labeled nuclei reached the ventricular surface and divided in three hours, as shown by numbers of labeled mitotic figures there, and virtually all mitotic nuclei in the ventricular surface were labeled at four to five hours. Unlabeled mitoses reappeared in the next few hours. On the twentieth day, in contrast, labeled mitoses did not appear until nearly six hours after H-3T.

Four to five hours after H-3T, the labeled cells had largely separated into three groups, one that had moved in toward the ventricular surface, including the dividing cells in fourteenth to nineteenth day stages, another remaining in the s-phase zone, and another just outside the s-phase zone. The latter cells had begun to migrate outward directly from the s-phase zone, and in the next several hours, throughout the pallium, substantial numbers of labeled cells had moved some distance into the migratory zone. In the sixteenth day experiment, the cells had moved about $75 \mu$ in five hours from the s-phase zone through the lateral migratory zone, after spending the first four hours following H-3T uptake in the proliferative zone (fig. 2). Measuring this distance along the shortest lines from the ventricular surface to the surface of the pallium, the more advanced cells appeared to have traveled nearly half way to the cortex, yet they would not even begin to arrive in the cortex for another day and a half. The reason for this paradox was that in the early hours of migration they first moved radially outward, but then began to turn, depending on the region, to conform during subsequent phases of migration to the regional fiber paths, forming columns and caravans of cells (fig. $3 A, B)$ as they traveled along them.

Some cells that moved directly outward from the proliferative zone divided en route, as shown by the following evidence. There were normally fairly numerous mitotic figures in a zone just outside the proliferative cell zone in the sixteenth to nineteenth day period. Cells in this region did not take up $\mathrm{H}-3 \mathrm{~T}$ at the time it was given, but in subsequent hours cells in mitosis in this region showed labeling, indicating that they had originated in the proliferative cell zone and had begun to move outward, dividing on the way.
2. Later phases of migrations up to the time of birth. From these earlier stages of migration the labeled cells continued to advance along their paths, and at 24 hours they tended to be concentrated in three zones: the proliferative zone, the deeper third of the migratory zone, and the middle to outer third of the migratory zone. By 48 hours (but a little longer in nineteenth to twenty-first day migrations) a few labeled cells were beginning to enter the cortical plate (fig. 4), others were in the outer third of the migratory zone, some passing through the lamina of polymorphous neurons of layer VI, and there was still a considerable number in the deepest part of the migratory zone. In the seventeenth day experiment substantially labeled cells had largely disappeared from the proliferative zone by 48 hours, either by migration or mitotic dilution of their labels, but in the eighteenth through the twenty-second day experiments, they lingered in the proliferative cell zone for longer periods. At 72 to 96 hours, labeled cells were numerous in the cortical plate, tending to be concentrated in its outer part except in the sixteenth day experiment where dorsally the destination of the labeled cells was in the deeper layers. The long axes of these intracortical cells lay perpendicular to the pallial surface, forming a continuum with the labeled cells still in the migratory zone and in the zone between the cortical plate proper and the polymorphous cell layer beneath it (fig. 3C). In the fourteenth day experiments, the labeled cells destined to be polymorphous neurons of the deepest part of layer VI could be seen in the earliest cortical plate, dorsally, 72 hours after H-3T.

By the time of birth to one day old, the labeled cells that had originated on the sixteenth to eighteenth day were essentially at their final cortical destinations, leaving only lightly labeled and unlabeled cells in the album cerebri. Most nineteenth day labeled cells had arrived in the cortex by the time of birth, but a few, now visibly recognizable as young neurons, were still moving through the cortex to the outer layers. Layers II and III were still incomplete at birth with a large number of neurons still to be added, as we now describe. 
3. Migrations that continued into postnatal life. Cells destined to be layer IV neurons, whichever day they originated, seemed to have all arrived in the cortex by about the time of birth, but they were present in the relatively undifferentiated outer cortex and did not become recognizable as a "cortical layer" until about four to five days after birth. How layer IV assumed its final position was revealed as much by the migrations of lightly labeled and unlabeled cells as by those of the substantially labeled cells. The matter was simply this, that around the time of birth in the seventeenth day experiment, the outer cortex (presumptive layers II, III, IV) was composed largely of labeled cells in its deeper two-thirds, with lightly labeled and a few unlabeled cells composing its outer third. In the next four or five days, considerable numbers of additional unlabeled and lightly labeled cells had moved through the cortex to increase the outermost layers, leaving the substantially labeled cells behind them at the deeper level, layer IV.

The unlabeled and lightly labeled cells just mentioned corresponded, of course, to the moderately to heavily labeled cells of the nineteenth, twentieth and twentyfirst day experiments, and to some of those of the eighteenth. Some aspects of the migrations originating on the twentieth and twenty-first intrauterine days illustrate how these last cells to be added to the cortex got there. Figure 5 shows photomicrographically some features of the twentieth day migration, and figure 1 relates this migration diagrammatically to that of the seventeenth day. About the time of birth, a considerable number of twentieth day labeled cells, forming an advanced cohort, had traveled to the outermost part of the cortex over the vertex, where they appeared as labeled neurons in that increasing population. Other labeled cells, most of them recognizable as young neurons, were en route at various levels of the isocortex, or just entering it. None had yet reached the outer cortex laterally or in the occipital and frontal poles. There was still a large number of labeled cells in the periventricular proliferative cell zone and in the migratory zone, forming a continuum with those entering the cortex; many of them would take another five days to reach the outer cortex as neurons, and some destined for layer II in the frontal pole would take seven (fig. 5). Some twentieth day labeled cells in the migratory zone on the day after birth later became neuroglia in the white matter, diluting their labels by successive divisions during early infancy. No twentieth day labeled cells, as such, migrated to the isocortex to become neuroglia, but some that migrated to the basal cortical regions did become neuroglia, holding their labels until several days after birth.

In the twenty-first day experiment the labeled cells also delayed in the migratory zone, and only a few had entered the cortex by the day after birth. Three days after birth, many were en route through the cortex, and a few were in their final positions as neurons in the outer cortex. Many labeled cells among the intracortical migrants could be recognized as neurons or neuroglia, but some could not be distinguished. By five days most migrants destined to be neurons had reached their destinations and labeled small neuroglia appeared throughout the cortex. Many neuroglia kept their labels up to ten days in the cortex, but not in the album cerebri. Virtually none in either region showed any label by three and one-half weeks.

\section{Effects of $16.4 \mu \mathrm{c}$ of $\mathrm{H}-3 \mathrm{~T}$}

The migrations of labeled cells in this experiment were similar to those in $4 \mathrm{uc}$ experiments, but a deleterious effect was expressed in another way. The number of neurons that ultimately made up layers II and III especially over the vertex was considerably diminished. The missing cells would correspond to lightly labeled and unlabeled cells of the $4 \mu \mathrm{c}$ experiments, cells that were granddaughters or later generations descended from those that originally took up the H-3T. One may speculate that the diminution was owing to a slowed mitotic rate in the proliferative zone during the period when the missing neurons should have been produced, or to enough mitotic cell deaths in the same period to produce the deficit. 


\section{DISCUSSION}

The experiments showed that the migratory cells traveled complex paths to the developing cortex leaving the proliferative zones to follow along the curving corticopetal fibers, only to leave them as they arrived at the cortical plate. Why and how they did this is unknown; we can only begin to think about them in terms of hypotheses that have been proposed, that neural cells (and their fibers) seek each other out owing to chemical attractants, or having made contact they stay together because of molecular affinities (Schmitt and Davison, '65; Sperry, '65).

The estimated speeds at which labeled migratory cells traveled and the distances they went were interesting to consider in three situations. In the sixteenth day experiment labeled cells began to move out of the s-phase zone into the lateral migratory zone about four hours after $\mathrm{H}-3 \mathrm{~T}$ reaching a distance of about $75 \mu$ in another five hours. Discounting curvature of the paths, they traveled at a rate of about $15 \mu$ per hour or $360 \mu$ per day. In other situations between the sixteenth and nineteenth day, some paths could be fairly well observed, because they lay in nearly frontal (vertical) planes at mid-pallium, extending from the level of the lateral part of the migratory zone to the vertex. This distance, noted earlier, grew relatively less rapidly than cortical thickness, from $1500 \mu$ to about $1800 \mu$ btween the sixteenth and twentieth days. The transit time to the developing cortex in this period was about 48 hours giving a speed of the order of $800 \mu$ per day. In the nineteenth day experiment, the most advanced labeled cells had not quite entered the developing cortex by 48 hours, but by 72 hours some had reached its outer part. During this 24 hour interval the thickness of the dorsal, mid-pallial cortex was about $400 \mu$; hence a speed of about $400 \mu$ per day.

These figures provide only a magnitude, 15 to $30 \mu$ per hour, once or twice the length of the cell body; estimates of them had broad margins for error. Beside few opportunities to trace an entire path, the system being measured was a growing spheroid. The destination of the labeled cells in fetal life was usually the outer part of the developing cortex, and because this kept growing it was an ever-receding target. On the sixteenth day, a cell in the lateral proliferative zone was about $1500 \mu$ away from the beginning dorsal cortical plate, but when it got there about four days later the now $250 \mu$ thick cortex added that much to its journey, which had also been increased by some $300 \mu$ of migratory zone growth. In migrations that continued into the first week after birth, as those originating on the twentieth intrauterine day (figs. $1,5)$, cells that delayed during migration, and reached their destinations almost ten days after they originated, were traveling through a kind of miniature relativistic expanding universe.

\section{LITERATURE CITED}

Angevine, J. B., and R. L. Sidman 1961 Autoradiographic study of cell migrations during histogenesis of cerebral cortex in the mouse. Nature, 192: 766-768.

1962 Autoradiographic study of histogenesis in the cerebral cortex of the mouse. Anat. Rec., 142: 210.

Berry, M., and A. W. Rogers 1965 The migration of neuroblasts in the developing cerebral cortex. J. Anat., 99: 691-709.

Bond, V. P., and L. E. Feinendegen 1966 Intranuclear ${ }^{3} \mathrm{H}$ thymidine: dosimetric, radiobiological and radiation protection aspects. Health Physics, 12: 1007-1020.

D'Amato, C. J, and S. P. Hicks 1965 Effects of low levels of ionizing radiation on the developing cerebral cortex of the rat. Neurol., 15: 1104-1116.

Hicks, S. P. 1954 Mechanism of radiation anencephaly, anophthalmia, and pituitary anomalies. Repair in the mammalian embryo. Arch. Path., 57: 363-378.

- 1958 Radiation as an experimental tool in mammalian developmental neurology. Physiol. Rev., 38: 337-356.

Hicks, S. P., M. C. Cavanaugh and E. D. O'Brien 1962 Effects of anoxia on the developing cerebral cortex in the rat. Am. J. Path., 40: 615635.

Hicks, S. P., and C. J. D'Amato 1961 How to design and build abnormal brains using radiation during development. In: Disorders of the Developing Nervous System, W. S. Fields and M. M. Desmond, eds. Charles C Thomas, Springfield, Illinois. Chap. 4, pp. 60-97.

1966 Effects of ionizing radiations on mammalian development. In: Advances in Teratology, D. H. M. Woollam, ed. Logos Press, Ltd., London. pp. 195-250.

Hicks, S. P., C. J. D'Amato, M. A. Coy, E. D. O'Brien, J. M. Thurston and D. L. Joftes 1961 Migrating cells in the developing nervous system studied by their radiosensitivity and tritiated thymidine uptake. In: Symposium on Fundamental Aspects of Radiosensitivity, Brookhaven National Laboratory, Upton, N. Y., Office 
of Technical Services, Department of Commerce, Washington, D. C., pp. 246-261.

Hicks, S. P., C. J. D'Amato and M. J. Lowe 1959 The development of the mammalian nervous system. I. Malformation of the brain, especially the cerebral cortex, induced in rats by radiation. II. Some mechanisms of the malformations of the cortex. J. Comp. Neur., 113: 435469.

Krieg, W. J. S. 1946 Connections of the cerebral cortex. I. The albino rat. A. Topography of the cortical areas. J. Comp. Neur., 84: 221275.

Sauer, F. C. 1935 Cellular structure of the neural tube. J. Comp. Neur., 63: 13-23.

Schmitt, F. O., and P. F. Davison 1965 Proteins in the developmental processes of the nervous system. Neurosciences Research Program Bulletin, Massachusetts Institute of Technology, 3: 61-62.
Sidman, R. L., and J. B. Angevine 1962 Autoradiographic analysis of time of origin of nuclear versus cortical components of mouse telencephalon. Anat. Rec., 142: 326-327.

Sidman, R. L., I. L. Miale and N. Feder 1959 Cell proliferation and migration in the primitive ependymal zone; an autoradiographic study of histogenesis in the nervous system. Exper. Neurol., 1 : 322-333.

Smart, I., and C. P. Leblond 1961 Evidence for division and transformations of neuroglia cells in the mouse brain, as derived from radioautography after injection of thymidine-H-3. J. Comp. Neur., 116: 349-367.

Sperry, R. W. 1965 Embryogenesis of behavioral nerve nets. In: Organogenesis, $R$. $L$. DeHaan and H. Ursprung, eds. Holt, Rinehart and Winston, New York. pp. 161-186. 


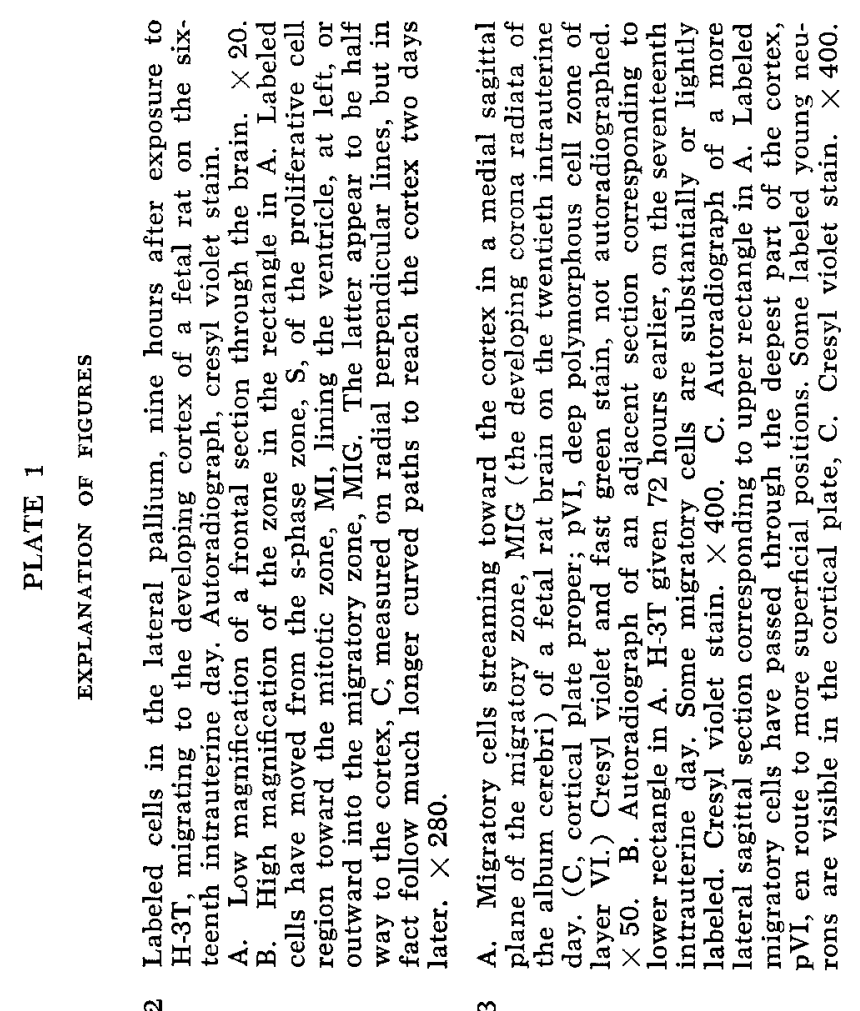



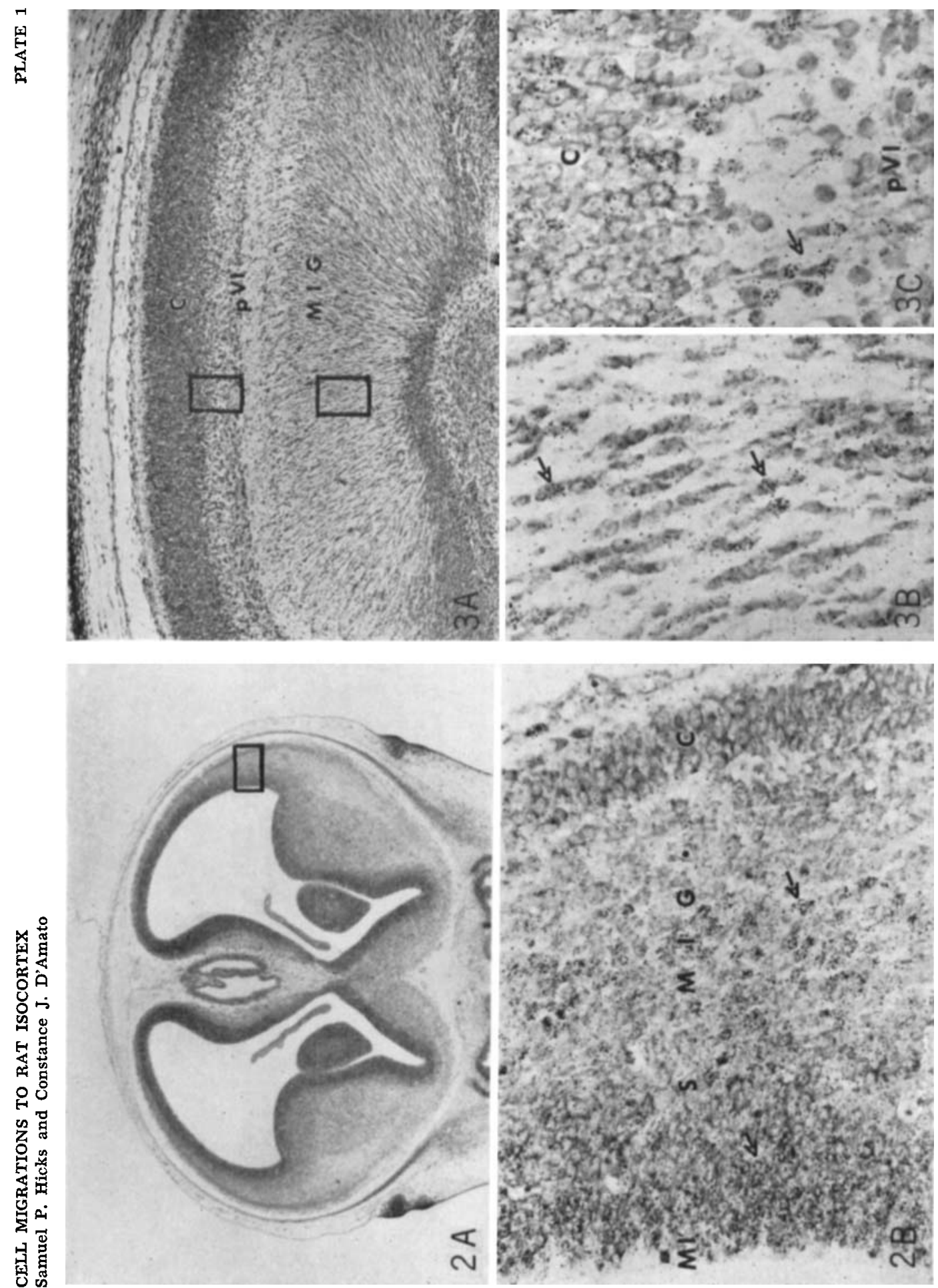


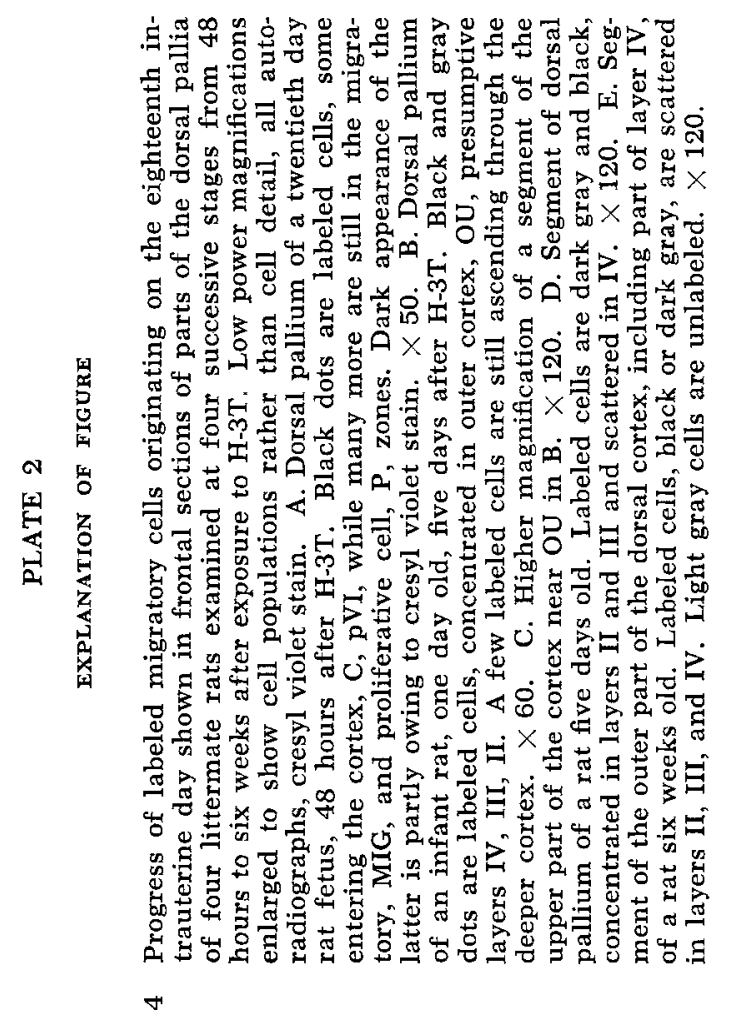



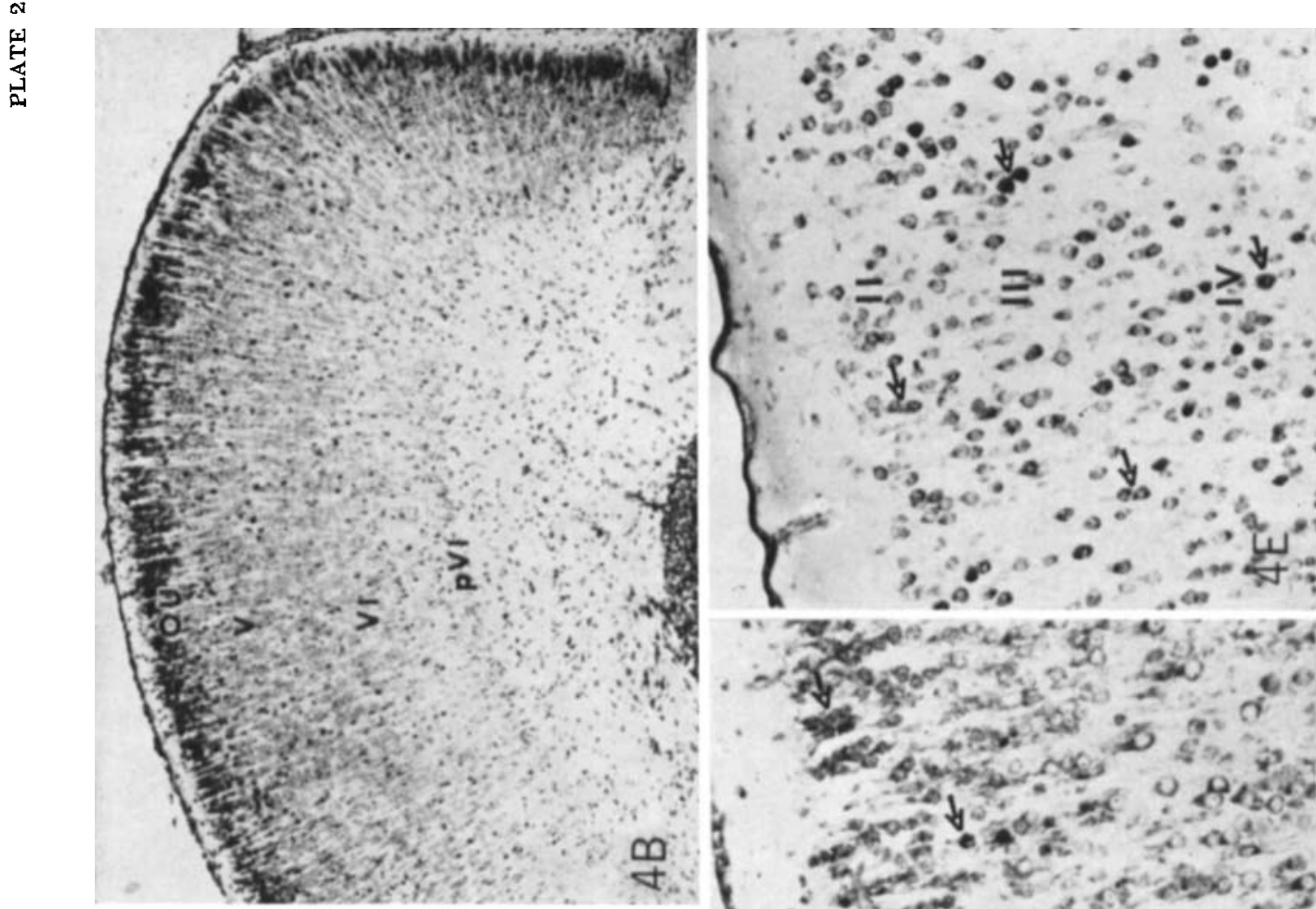

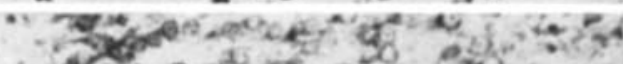

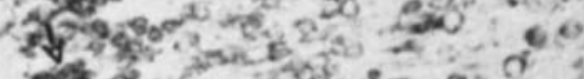

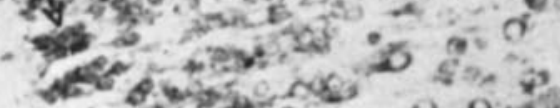

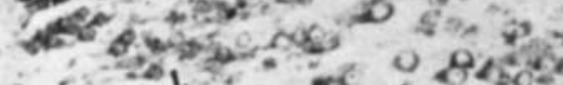

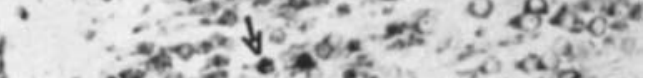

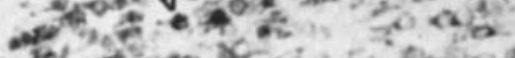

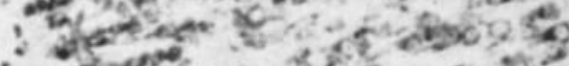

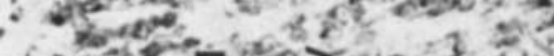

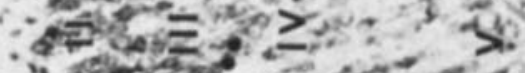

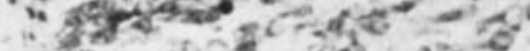

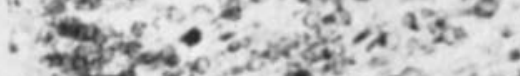

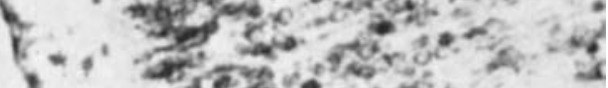

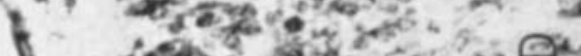

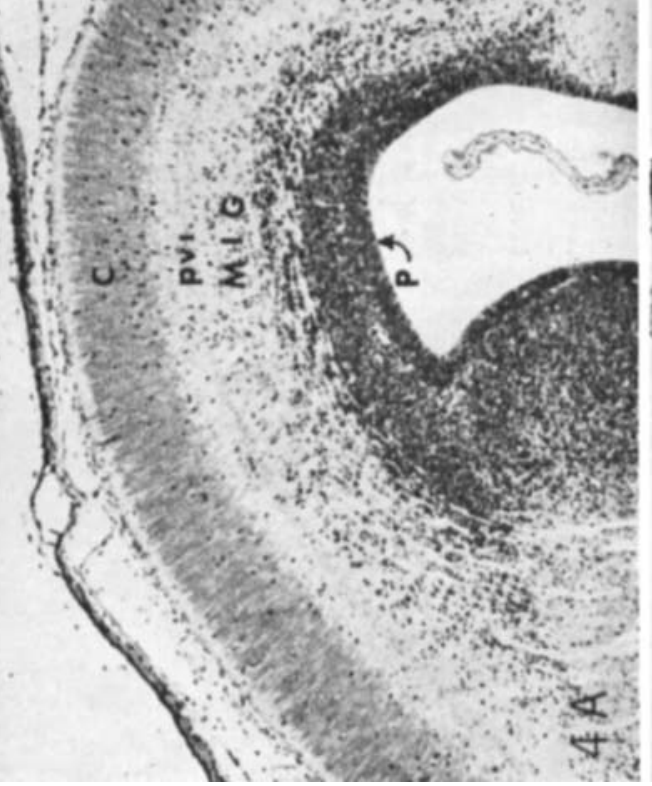
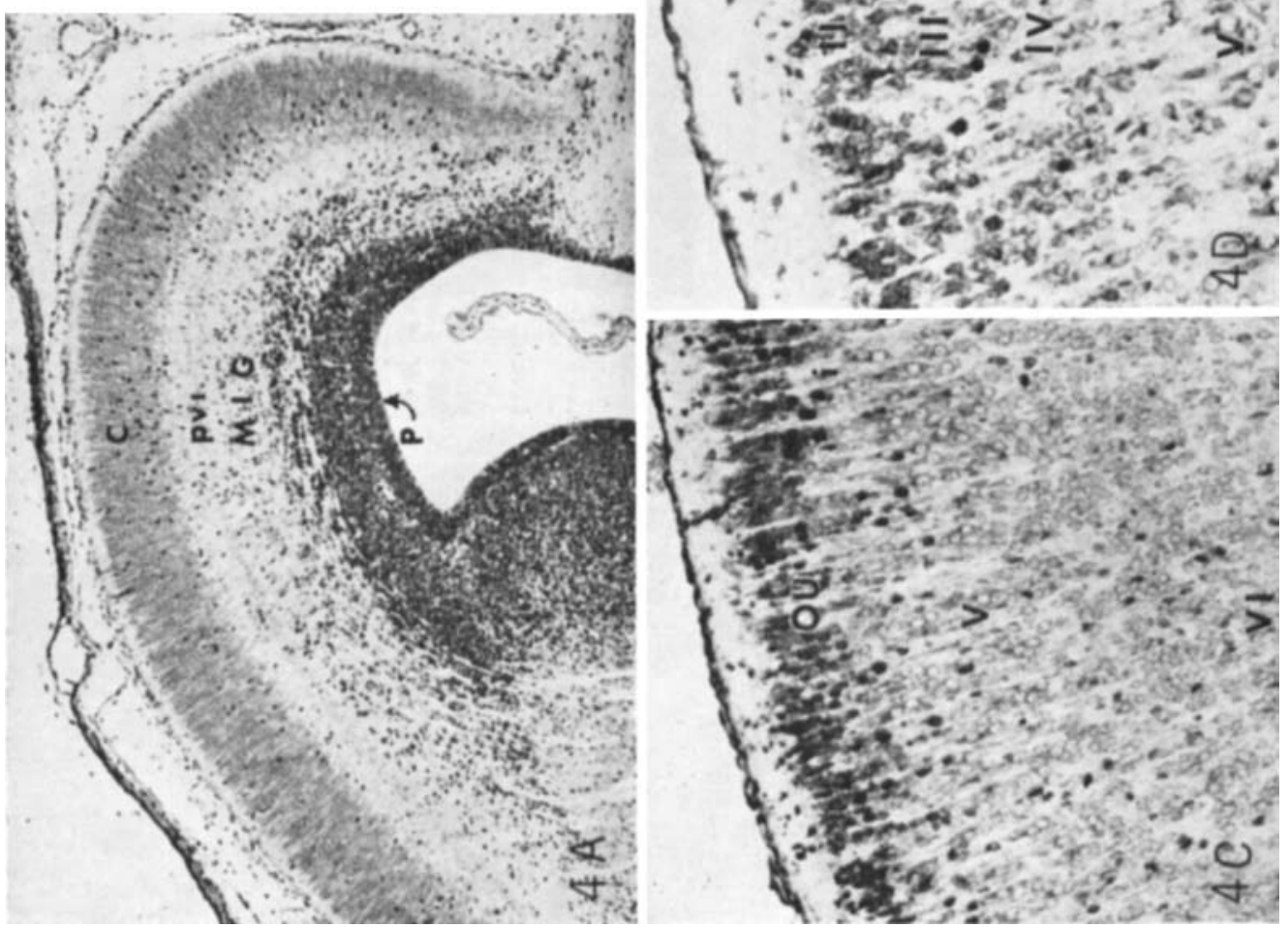


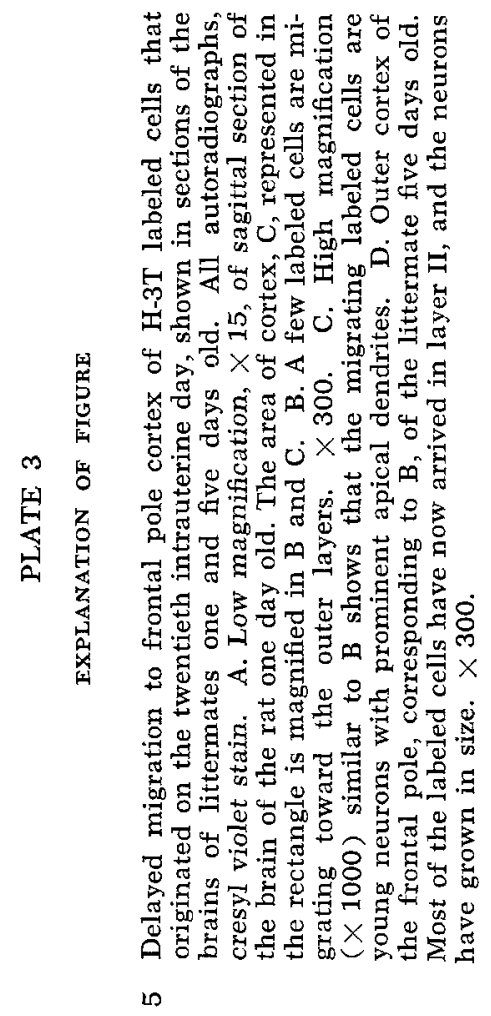


且

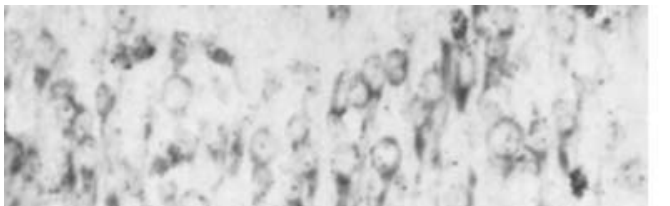

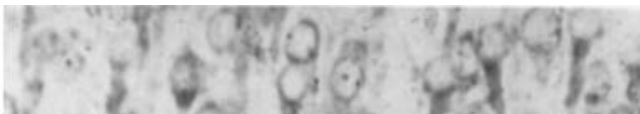
2. 0 ग 1 (n) $3^{2}, 4$ 7ow $1 / 3$ o ox tos 64t a ory is $7 x$ or 192 Mhork yol 5 D. 10 ,

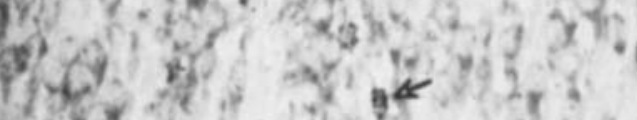
in 102010

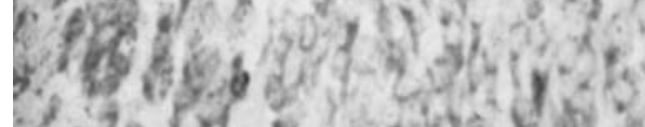
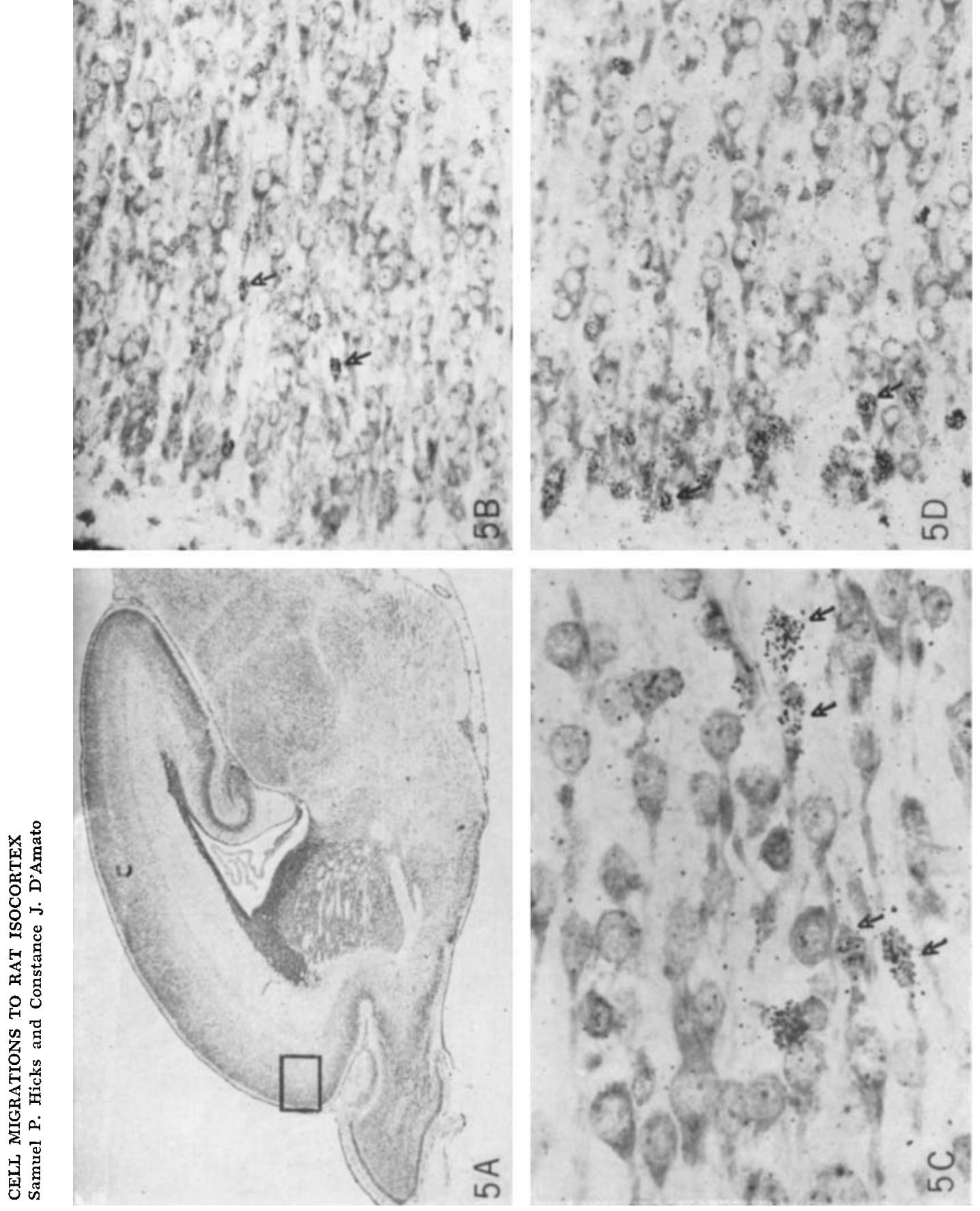